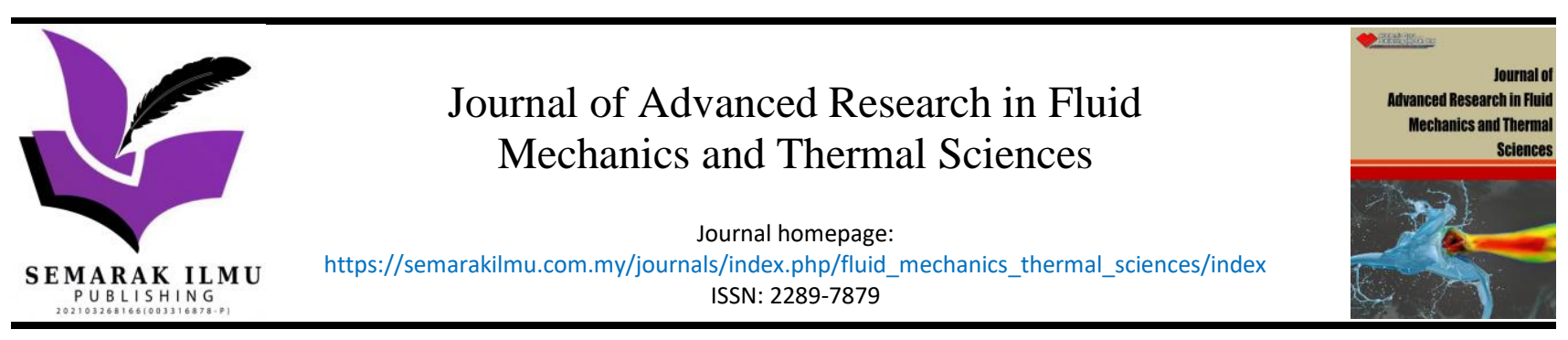

\title{
Effect Of Design Parameters of Serpentine-Shaped Flat Plate Solar Collector Under Malaysia Climate Conditions
}

\author{
Mohd. Amirul Hilmi Mohd Hanoin ${ }^{1}$, Nor Amirah Safiah Muhamad ${ }^{1}$, Nadzirah Mohd Mokhtar ${ }^{1, *}$, \\ Amir Abdul Razak², Muhamad Sukri Hadi ${ }^{3}$ \\ Faculty of Civil Engineering Technology, Universiti Malaysia Pahang, Lebuhraya Tun Razak, 26300 Kuantan, Pahang, Malaysia \\ Faculty of Mechanical and Automotive Engineering Technology, Universiti Malaysia Pahang, 26600 Pekan, Pahang, Malaysia \\ School of Mechanical Engineering, Universiti Teknologi MARA, 40450, Selangor, Malaysia
}

\section{ARTICLE INFO ABSTRACT}

Article history:

Received 30 May 2021

Received in revised form 28 August 2021

Accepted 2 September 2021

Available online 18 October 2021

\section{Keywords:}

Serpentine-shaped flat plate solar collector; solar water heating; solar thermal collector; thermal efficiency; renewable energy

\begin{abstract}
Solar thermal energy plays a vital role in the industrial sector, especially for water heating applications. Further research to improve the efficiency of flat plate solar collectors by focusing on collector design modification is imperative. This research aimed to carry out an experimental investigation on comparative designs and fabrication approaches that deal with the analysis of flat plate solar collector thermal performance, thermal efficiency, the effect of various mass flow rates, and pressure drop analyses. In this paper, a different design modification of pipe collector with serpentine-shaped was established with different tube diameters (3/4-inch and 3/8-inch), and different pipe spacing (18.5 $\mathrm{cm}$ and $27.0 \mathrm{~cm}$ ). Under the same heat radiation intensity and constant mass flow rate, a pipe collector with a tube diameter of 3/4-inch achieved $3.5 \%$ and $9.4 \%$ higher thermal performance and collector efficiency respectively compared to the tube diameter of $3 / 8$ inch. Furthermore, the pipe collector with pipe spacing of $18.5 \mathrm{~cm}$ exhibited $4.3 \%$ and $12.6 \%$ higher thermal performance and collector efficiency respectively compared to pipe spacing of $27 \mathrm{~cm}$. The relationship between collector efficiency and temperature difference was also investigated. Moreover, the effect of different mass flow rates was studied upon and it was found that a flow rate of $0.03 \mathrm{~kg} / \mathrm{s}$ exhibited optimum thermal performance for the pipe collector. Additionally, a pressure drop was observed with the increase in flow rate, while decreases when the fluid temperature increases.
\end{abstract}

\section{Introduction}

The increase in the cost of fossil fuel with unknowing of their reserves has encouraged researchers to intensify the study on renewable energy, which is seen as the best solution for the ongoing energy crisis and environmental pollution. Among the renewable energy available, solar energy is one of the most ideal energy sources that does not contribute to global warming [1-3]. Solar thermal collector (STC) is one of the most widely known applications to harness solar energy. This research work used a flat plate solar collector (FPSC) as a non-concentrating STC. FPSC is known as a

\footnotetext{
* Corresponding author.

E-mail address: nadzirah@ump.edu.my
}

https://doi.org/10.37934/arfmts.88.1.7180 
conventional solar energy-exploiting device and is the foundation of domestic solar water heating worldwide $[4,5]$.

Design modification is a facile way where tweaking parameter can help to improve the compatibility of a solar energy harvesting device. Based on the literature, there are plenty of contributions from researchers in means to further enhance the performance of FPSCs. Deeyoko et al., [6] investigated the effects of thermal performance enhancers on flat plate solar water heaters. Results show that the rectangular internal fins exhibited 18-20\% higher energy efficiency compared to the plain tube. Hossain et al., [7] conducted an energy, exergy, and economic analysis for a twoside serpentine flow system based on a newly developed integrated solar photovoltaic and thermal collector with phase change materials (PV/T-PCM) module. The results showed that the PV/T-PCM systems are more economical compared to the solar system alone. Zhou et al., [8] investigated the temperature distribution of a serpentine tube type integrated solar photovoltaic and thermal collector. The experimental and simulation results proved that the most effective way to ensure uniformity in plate temperature distribution was by using absorber materials with better thermal conductivity and reducing the tube spacing. Wang et al., [9] performed experimental studies on serpentine flat plate collectors with different pipe parameters and new phase change collectors. The result showed that the larger tube diameter and smaller pipe spacing (S) exhibited the highest collector efficiency. Sachit et al., [10] investigated a comparative simulation study for absorber design between serpentine and serpin-Direct under solar radiation between 300 to $1100 \mathrm{~W} / \mathrm{m}^{2}$. Based on the thermal efficiency result, the absorber design with serpentine-shaped shows slightly higher by $53 \%$ compared to serpen-Direct design with $52 \%$ at a mass flow rate of $0.09 \mathrm{~kg} / \mathrm{s}$. There were also the studies on photovoltaic thermal collector equipped with serpentine-shaped collector purposely to reduce the operating temperature whiles increasing its efficiency and energy output of solar panel photovoltaic [11,12].

Several comprehensive experimental studies and numerical investigations have been conducted to study the massive heat loss near the contact region due to poor thermal characteristics of the working fluid. To address the deficiency, the concept of tube rotation was introduced by Norouzi et al., [13] to reduce the maximum temperature of the tube and to make its distribution on the tube more uniform. Bezaatpour and Rostamzadeh [14] studied the numerical investigation of innovative and cost-effective design by equipping the flat plate collector with revolutionary tubes and magnetic field inducer. By integrating both rotary tubes and magnetic inducer, their results revealed a $17.3 \%$ enhancement from current performance in the optimal condition, which is $31 \%$ of the energy loss, could be restored in the FPSC. Another study also from the same author discussed the performance of rotating collector pipes for simultaneous pressure drop and thermo-exegetic enhancement [15]. Results depict the newly designed collector showed a reduction of pressure drop and pumping power, whiles the energetic performance enhance $5.8 \%$ in an optimal condition. On the other hand, the authors also implementing a rotary absorber tube and magnetic field inducer with Nano fluid simultaneously on the Parabolic Through Solar Collector (PTSC) to overcome the deficiencies [16].

To the best of our knowledge, there is no study reported on the effect of design parameters on the fabrication part of a small-scale serpentine-shaped flat plate solar collector, especially in Malaysia. The prime concern of this research is to develop a highly efficient small-scale solar collector under the typical Malaysian climate. Therefore, one of the approaches to boost up the thermal efficiency of the STC system is through design modification. In this paper, the effect of different parameters, for the absorber part of the serpentine-shaped flat plate collectors were investigated. Thermal performance and collector efficiency were also evaluated as the target outputs. The influence of mass flow rate concerning the pressure drop was also studied upon. 


\section{Methodology}

Four different parameters set of serpentine-shaped copper pipes were fabricated with tube diameter, $\mathrm{D}$ (3/4-inch and 3/8-inch) and pipe spacing, $\mathrm{S}(18.5 \mathrm{~cm}$ and $27 \mathrm{~cm})$. The detailed geometrical dimension of the absorber collector of the serpentine-shaped confirmed that they have the same collector area $(60 \mathrm{~cm} \times 90 \mathrm{~cm})$. A glass was placed on top of the collector to prevent heat loss to the surroundings as shown in Figure 1. The small-scale FPSC testing unit used in the research work is shown schematically in Figure 2. The unit was fabricated as a compact system with one loop only. The setup comprises of absorber, piping, and heat exchanger section. The bent copper coil was attached to the absorber plate that had been sprayed black to increase the absorbance rate. Prior to this design, high thermal energy is usually transferred due to the largest surface areas. Due to the stratification temperature of the water inside the feed tank, three LCD thermometer digital were installed at different locations, namely at the top, middle, and bottom to measure the average temperature to minimize error in reading. Also, the inlet and outlet temperature on the heat exchanger at the feed tank equipped with LCD thermometer digital, whiles inlet and outlet collector section were measured by using Digital LCD water flow sensor and thermocouples. The heat radiation intensity remained constant during the experiment by using an indoor solar simulator. The solar simulator comprises eighteen units of 300W halogens lamps with installed by a voltage regulator to control the light intensity. A pyrometer was used to measure the radiation, and the ambient temperature was monitored to ensure it could be controlled with minimal fluctuation. The water flow rate was controlled using a manual valve and monitored by a flow meter sensor. A $12 \mathrm{~V}$ direct current (DC) water pump was installed to circulate the heat transfer fluid throughout the system. In this work, the prime objective is to calculate the efficiency of the FPSC using mathematical relations. The experimental data were collected based on its operation employing different collector designs in terms of tube diameter and pipe spacing.

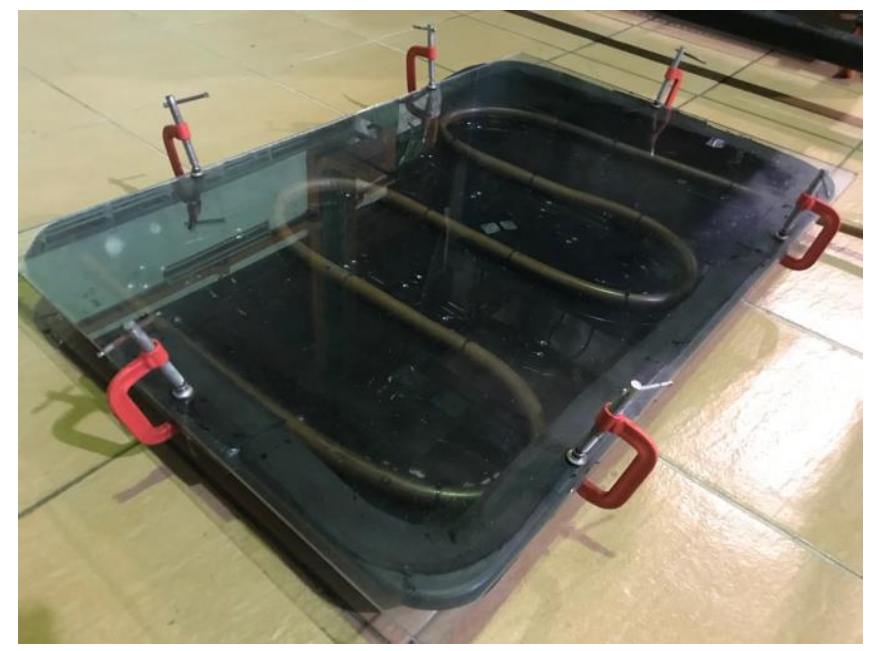

Fig. 1. Absorber collector with glass placed on top 


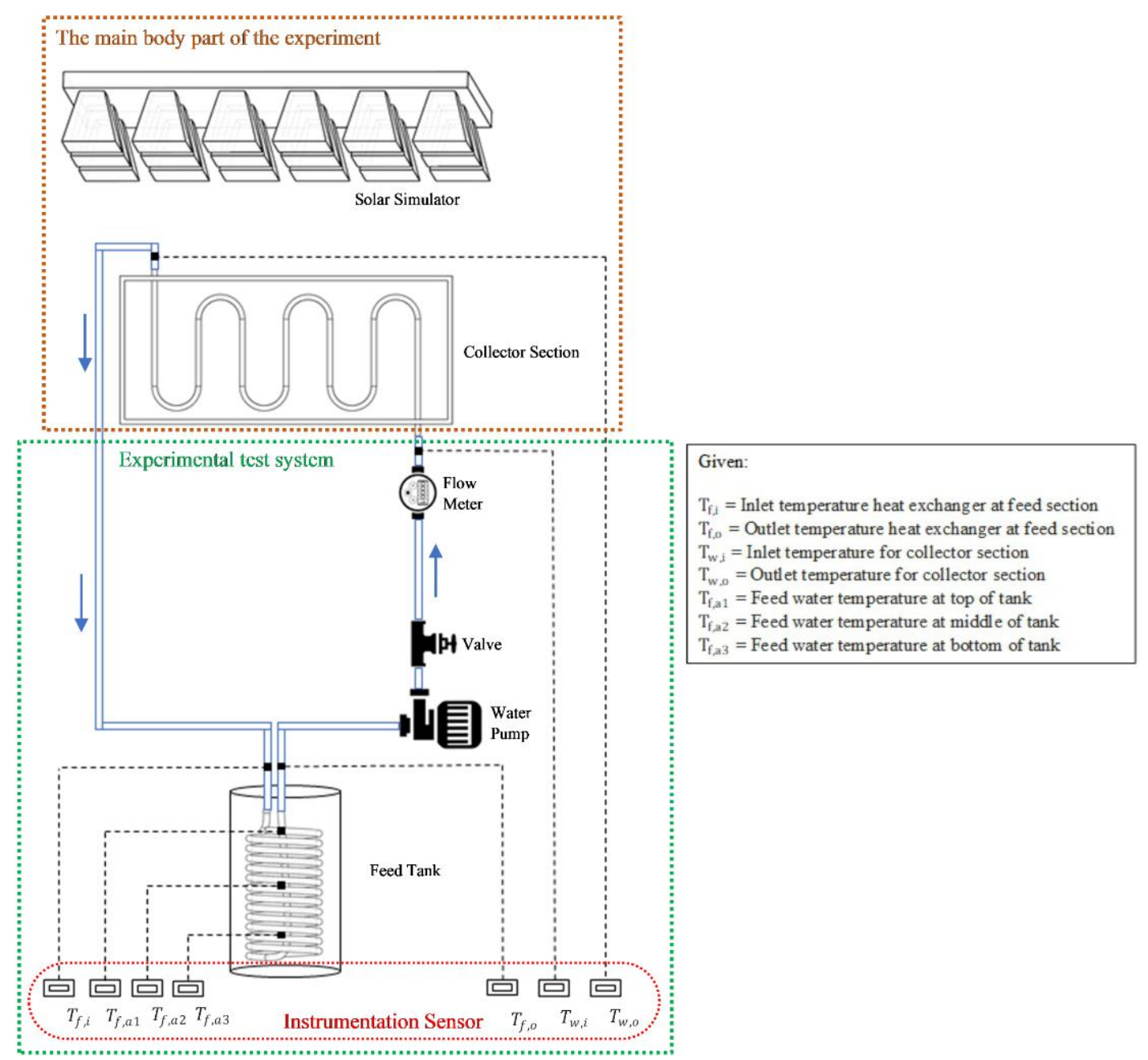

Fig. 2. Schematic diagram of the FPSC system

\subsection{Mathematical Formulations}

The thermal efficiency of the FPSC was calculated using the following formulae as shown below $[17,18]$. Mathematically, it is the ratio of the useful heat delivered to water to the total input energy. The useful energy is the difference between the heat absorbed and heat loss. However, since the mass flow rate of water flowing through the collector, $\dot{m}$ is a known value, the useful heat can also be calculated from Eq. (1).

$Q_{u}=\dot{\mathrm{m}} c_{p}\left(T_{w, o}-T_{w, i}\right)$

$Q_{i}=I A$

where $c_{p}, T_{w, o}$, and $T_{w, i}$ are the specific heat, outlet and inlet collector temperatures for water, respectively. Therefore, Eq. (3) can be used to define the thermal efficiency of the FPSC:

$\eta_{c}=\frac{\dot{\mathrm{m}} c_{p}\left(T_{W, o}-T_{w, i}\right)}{I A}$

To identify the flow of working fluid through the collector, the pressure drop can be calculated using Eq. (4). 
$\Delta P=\frac{128 \mu L \dot{m}}{\rho \pi D^{4}}$

where $\mu$ is the dynamic viscosity that changes to time and is inversely proportional to the temperature of the fluid, $L$ is pipe length in meter, $\rho$ is the density of water with $998 \mathrm{~kg} / \mathrm{m}^{3}$, and $D$ is the inner diameter of tube collector.

\section{Results and Discussion}

Experimental observations were taken in an indoor environment by using solar simulators. The results are more reliable as they can minimize the effect of fluctuating environmental conditions to identify the advantages of the modified collector. The collector efficiency is corresponding to the intensity of solar radiation and the angle of incidence to the absorbing section of the collector. Figure 3 and Figure 4 show the effect of different parameters concerning the outlet collector temperature and collector efficiency, respectively. Figure 3 is corresponding to the effect of different tube diameters, while Figure 4 depicts the effect with different pipe spacing. The data were recorded based on constant solar radiation and mass flow rate within 2 hours. With constant pipe spacing, data in Figure 3 indicates that the pipe collector with a tube diameter of $3 / 4$-inch achieved $3.5 \%$ and 9.4\% higher outlet collector temperature and collector efficiency, respectively, compared to a 3/8inch tube diameter collector. This highlights the fact that a larger tube diameter tends to create a larger surface area that could better absorb energy. In addition, the area of the collector is directly proportional to the outlet collector water temperature. As time passes, the thermal energy was continuously converted from solar radiation and transmitted to the water inside the feed tank. Furthermore, the collector efficiency data elucidated in Figure 3 showed a drastic increase within the first 30-minutes. This phase is known as the initiation phase as the solar radiation is constantly absorbed by the collector and converted into energy via increasing the water temperature. However, the data also showed that the temperature achieved a steady-state after 30-minutes. This is known as the stabilization phase as both feed and collector temperatures have achieved equilibrium. This is due to the heat loss to the surroundings. As stated by Newton's law of cooling, the rate of cooling is proportional to a temperature difference between the working fluid in the tube and plate [19]. As temperature difference maintains or decreases, heat transfer from the absorbing plate to the working fluid also decreases. Moreover, the heat is a form of low-grade energy that can be changed and cannot be stored long as it would dissipate to the surrounding. However, at this moment, the feed water temperature will constantly increase because of the continuous thermal energy transmission from the collector. Prolonged exposure time and increased solar radiation led to convective, radiative, entropy, and exergy losses while minimalizing the gain of useful energy at a higher intensity as compared to optimum conditions [20]. 


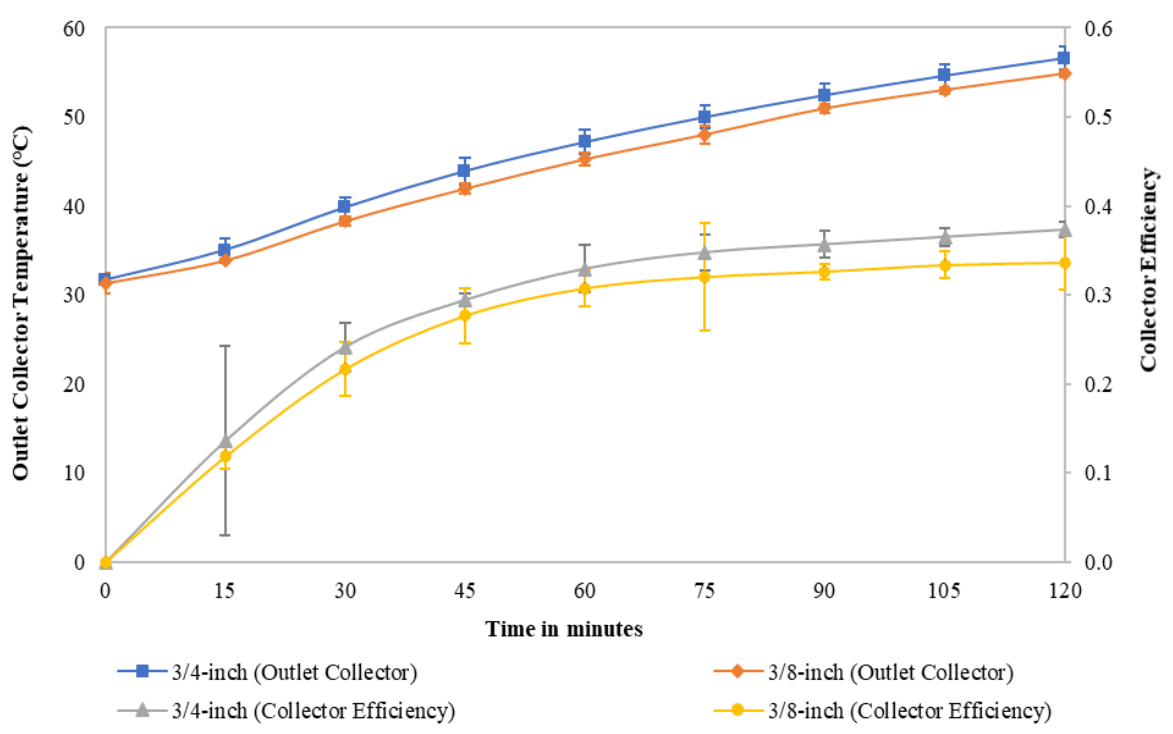

Fig. 3. Effect of different tube diameter on outlet collector temperature and collector efficiency

Figure 4 elucidates that the pipe collector with pipe spacing of $18.5 \mathrm{~cm}$ exhibited $4.3 \%$ and $12.6 \%$ higher outlet collector temperature and collector efficiency, respectively, compared to $27 \mathrm{~cm}$ pipe spacing. The smaller pipe spacing led to a higher number of turns that could fit on the collector absorber. The higher number of turns means a larger surface area between pipe tube and water, which allows greater thermal absorption. Moreover, the larger contact area between the water and pipe collector promotes higher thermal energy transfer. However, the collector efficiency graph in Figure 4 shows the same patterns as in Figure 3. The reasoning behind the similar pattern in both Figure 3 and Figure 4 are similar. As shown in Figure 5, the pipe collector with a diameter of 3/4-inch and pipe spacing of $18.5 \mathrm{~cm}$ was chosen for further experimentation and analysis. The temperature difference between outlet and inlet collector was proportional to the collector efficiency. This phenomenon occurred due to the higher thermal energy attained when a higher temperature difference was achieved. The collector design played an important role in achieving higher temperature differences which led to improved absorbance and transmission of heat energy. Furthermore, this can be proven, as shown in Eq. (3).

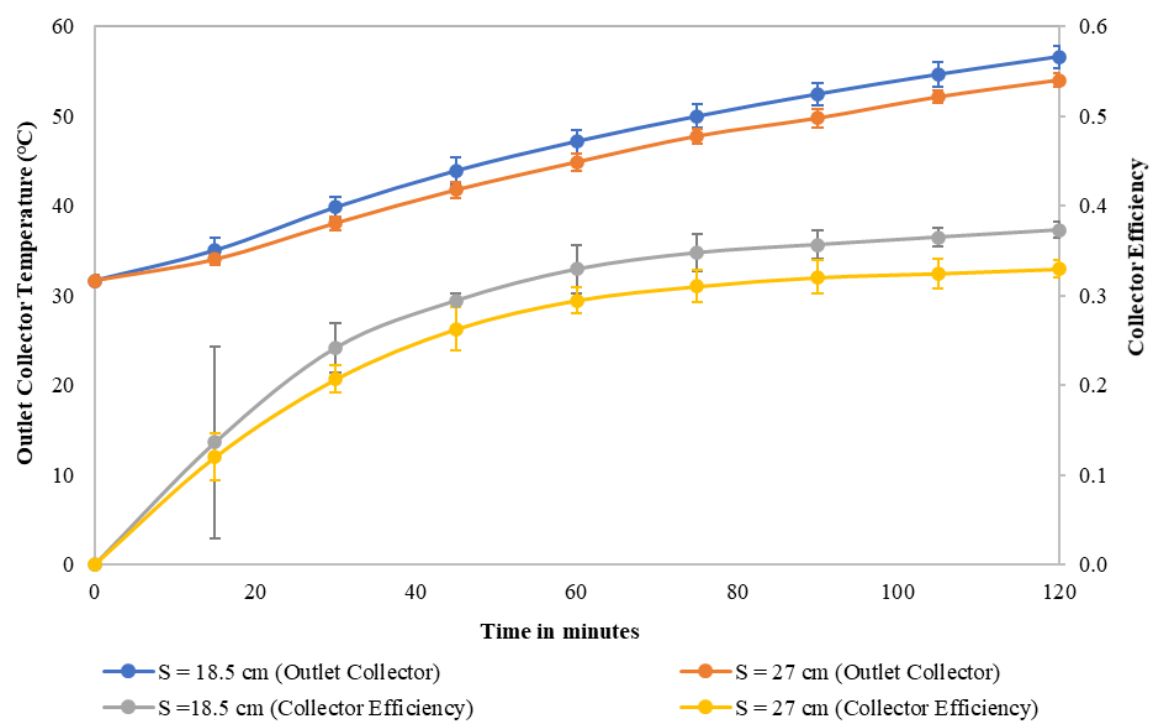

Fig. 4. Effect of different pipe spacing to outlet collector temperature and collector efficiency 


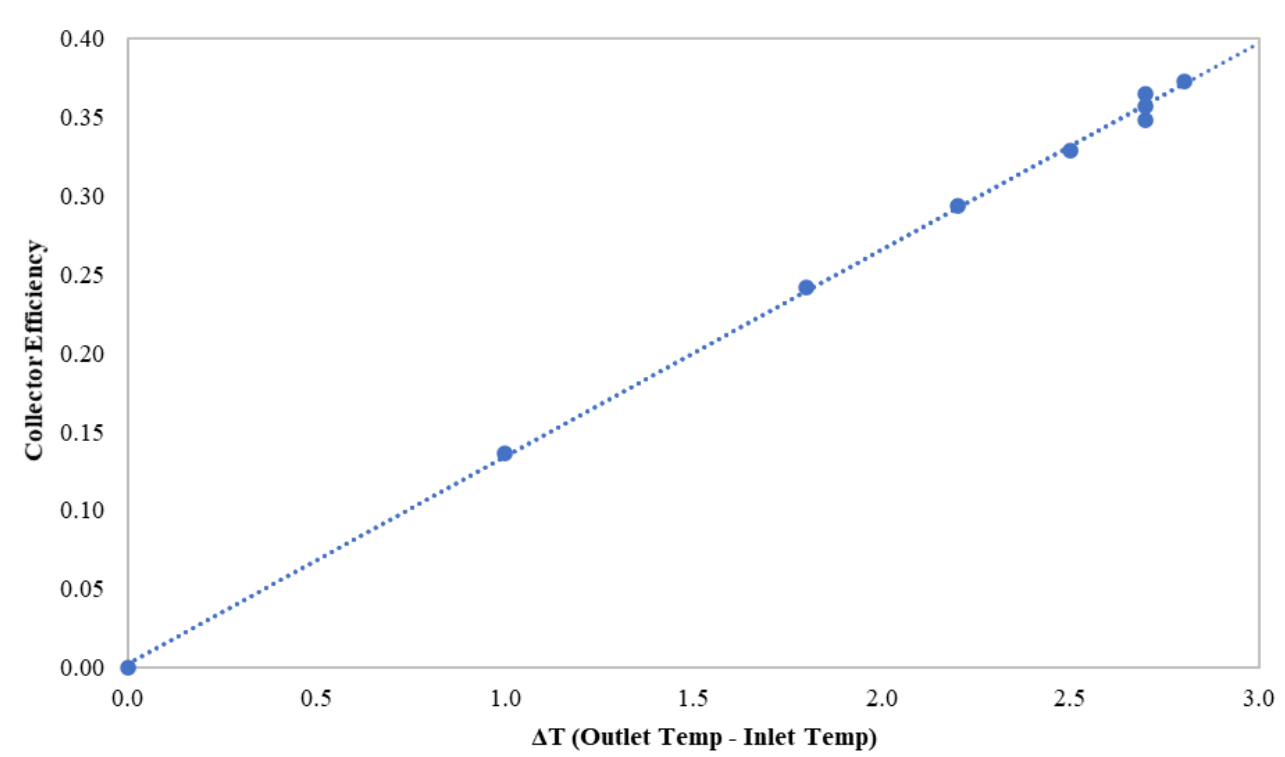

Fig. 5. Relationship between collector efficiency and temperature difference

Figure 6 describes the performance of a serpentine-shaped collector using a 3/4-inch tube diameter with a pipe spacing of $18.5 \mathrm{~cm}$ with a variation of mass flow rate at increasing radiation intensity. The results revealed that efficiency increases with mass flow rate reached a maximum in the range of $0.025 \mathrm{~kg} / \mathrm{s}$ to $0.035 \mathrm{~kg} / \mathrm{s}$ for a given intensity of radiation. Optimum thermal performance for given intensity reaches approximately $0.03 \mathrm{~kg} / \mathrm{s}$. It decreases with a further increase in mass flow rate. This is due to losses in terms of pressure drop, friction and entropy. Entropy losses happen because of heat transfer from the system to its surroundings, pressure losses and irreversible frictional heat generation losses. Also, the thermal energy further increases with enhanced radiation intensity. The optimum intensity of radiation for thermal energy is maximum in the range of 1000 $1050 \mathrm{~W} / \mathrm{m}^{2}$. The losses of exergy and entropy occur with a further increase in radiation intensity. Convective and radiative losses increase more steeply compare to gain in useful energy from incident radiation at an intensity higher than optimum.

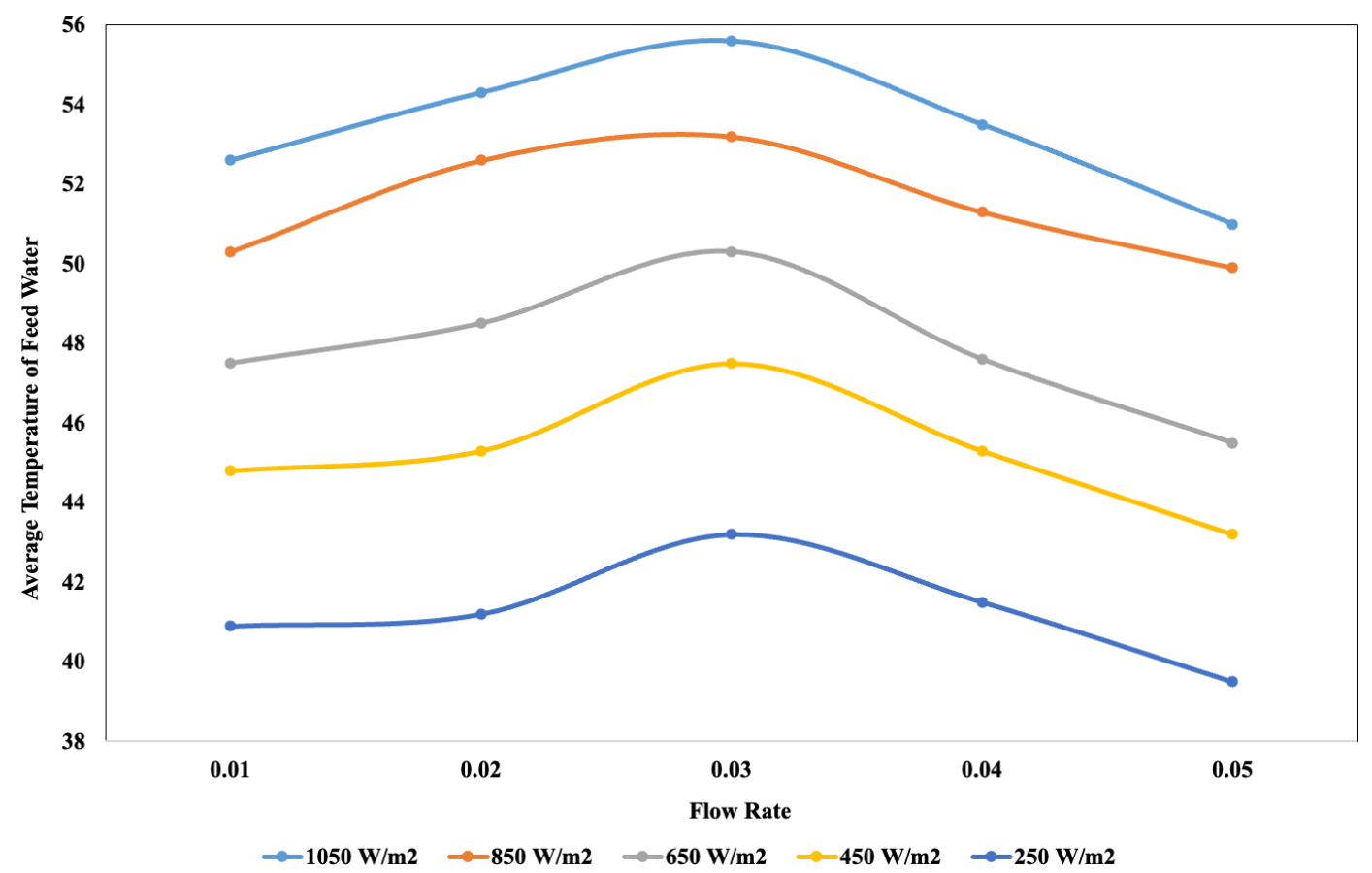

Fig. 6. Effect of different mass flow rate concerning the radiation intensity 
Figure 7 indicates the comparative pressure drop with respect to various mass flow rates for the serpentine-shaped collector by 3/4-inch tube diameter and pipe spacing of $18.5 \mathrm{~cm}$. As a result, the pressure drop increase as the mass flow rate increases, while decreases significantly when the fluid temperature increases. At 120 minutes, the working fluid has a higher temperature due to constant thermal energy gain. However, pressure drop decreases with respect to dynamic viscosity that decreases as the temperature of fluid increases. The dynamic viscosity is directly proportional to the pressure drop as calculated using Eq. (4). Due to the serpentine-shaped design, the geometrical shape caused a frictional pressure drop inside the pipe. This research study suggests that the working fluid must be at a higher temperature to minimize the pressure drop.

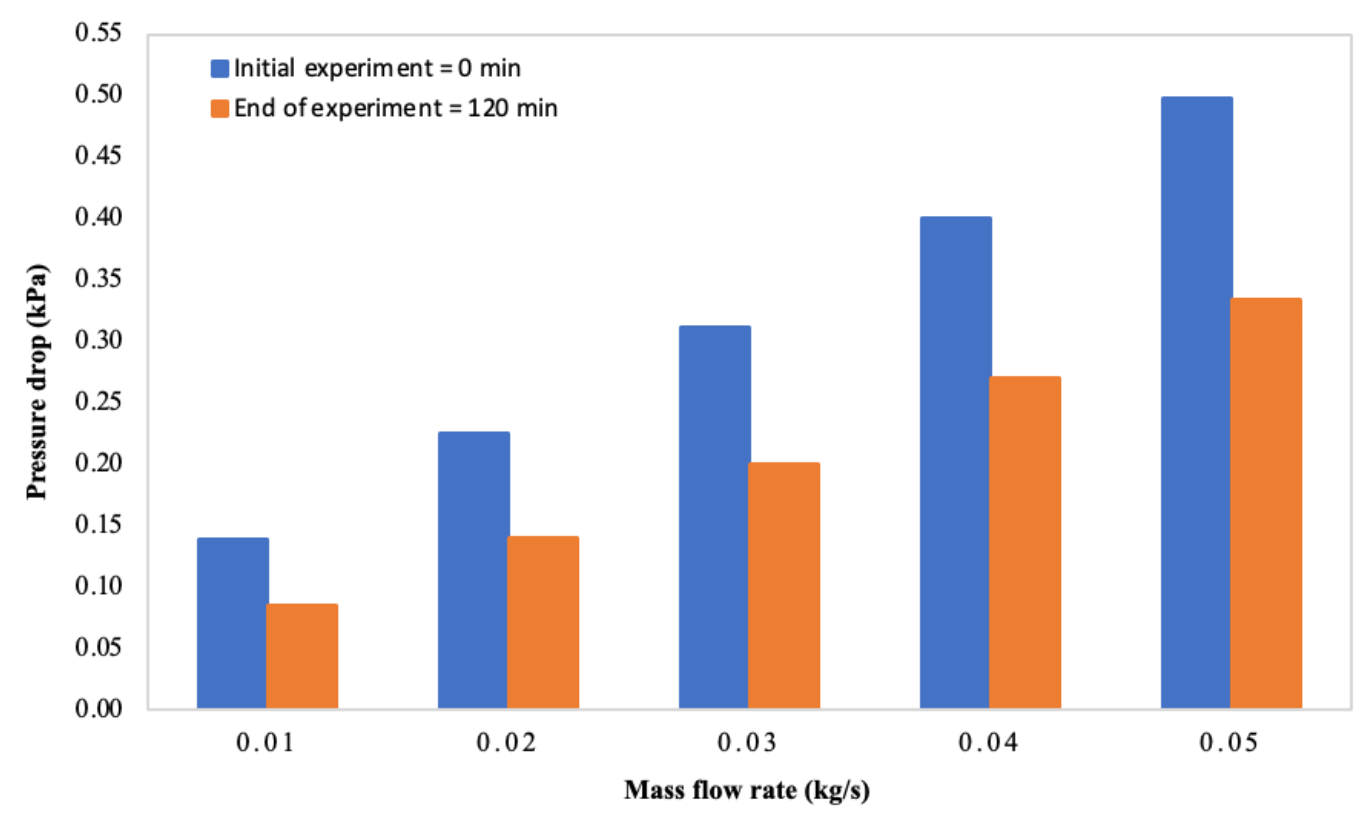

Fig. 7. Effect of mass flow rate with comparative initial and ending of the experiment

\section{Conclusion}

The purpose of this research was to investigate the thermal performance and efficiency of serpentine-shaped collector FPSC systems with different tube diameter and pipe spacing parameters under typical Malaysian weather conditions. Additionally, the effect of various mass flow rates and pressure drop analyses were also conducted to understand the total performance of the system from a technical viewpoint. Based on the experimental results, a pipe collector with a tube diameter of 3/4-inch achieved 3.5\% and 9.4\% higher thermal performance and collector efficiency respectively, compared to a tube diameter of 3/8-inch due to a larger contact area with the surface. With the same tube diameter ( $3 / 4$ inch), pipe spacing of $18.5 \mathrm{~cm}$ tends to attain higher thermal performance and collector efficiency by $4.3 \%$ and $12.6 \%$, compared to pipe spacing of $27 \mathrm{~cm}$. An optimal working condition can be achieved at $0.03 \mathrm{~kg} / \mathrm{s}$ of mass water flow rate and $1050 \mathrm{~W} / \mathrm{m}^{2}$ of heat radiation intensity for the highest average temperature in the water tank. Also, the pressure drops increases with the increase of mass flow rate, while its decreases when the fluid temperature increases.

\section{Acknowledgements}

The authors gratefully acknowledge Universiti Malaysia Pahang (UMP) for its financial support under the grant number RDU190395 and PGRS1903212. Sincere gratitude also expressed to UMP for providing MRS scholarship. 


\section{References}

[1] Jamar, A. M. Z. A. A., Z. A. A. Majid, W. H. Azmi, M. Norhafana, and A. A. Razak. "A review of water heating system for solar energy applications." International Communications in Heat and Mass Transfer 76 (2016): $178-187$. https://doi.org/10.1016/j.icheatmasstransfer.2016.05.028

[2] Wang, Zhangyuan, Wansheng Yang, Feng Qiu, Xiangmei Zhang, and Xudong Zhao. "Solar water heating: From theory, application, marketing and research." Renewable and Sustainable Energy Reviews 41 (2015): 68-84. https://doi.org/10.1016/j.rser.2014.08.026

[3] Hanoin, M. A. H. M., N. S. Mohammed, M. A. I. Z. Arris, A. I. A. Bakar, N. M. Mokhtar, and A. A. Razak. "Fabrication and performance evaluation of integrated solar-driven membrane distillation system with serpentine-shape of flat plate solar collector for seawater desalination." Journal of Applied Membrane Science \& Technology 23, no. 3 (2019): 49-63. https://doi.org/10.11113/amst.v23n3.163

[4] Pandey, Krishna Murari, and Rajesh Chaurasiya. "A review on analysis and development of solar flat plate collector." Renewable and Sustainable Energy Reviews 67 (2017): 641-650. https://doi.org/10.1016/i.rser.2016.09.078

[5] Vengadesan, Elumalai, and Ramalingam Senthil. "A review on recent development of thermal performance enhancement methods of flat plate solar water heater." Solar Energy 206 (2020): 935-961. https://doi.org/10.1016/i.solener.2020.06.059

[6] Deeyoko, L. Anto Joseph, K. Balaji, S. Iniyan, and C. Sharmeela. "Exergy, economics and pumping power analyses of flat plate solar water heater using thermal performance enhancer in absorber tube." Applied Thermal Engineering 154 (2019): 726-737. https://doi.org/10.1016/j.applthermaleng.2019.03.135

[7] Hossain, M. S., A. K. Pandey, Jeyraj Selvaraj, Nasrudin Abd Rahim, M. M. Islam, and V. V. Tyagi. "Two side serpentine flow based photovoltaic-thermal-phase change materials (PVT-PCM) system: Energy, exergy and economic analysis." Renewable Energy 136 (2019): 1320-1336. https://doi.org/10.1016/j.renene.2018.10.097

[8] Zhou, Jicheng, Haoyun Ke, and Xiaoqing Deng. "Experimental and CFD investigation on temperature distribution of a serpentine tube type photovoltaic/thermal collector." Solar Energy 174 (2018): 735-742. https://doi.org/10.1016/j.solener.2018.09.063

[9] Wang, Dengjia, Xiaowen Wang, Yingya Chen, Wenjun Kang, and Yanfeng Liu. "Experimental Study on Performance Test of Serpentine Flat Plate Collector with Different Pipe Parameters and a New Phase Change Collector." Energy Procedia 158 (2019): 738-743. https://doi.org/10.1016/i.egypro.2019.01.197

[10] Sachit, Fadhil Abdulameer, Mohd Afzanizam Mohd Rosli, Noreffendy Tamaldin, Suhaimi Misha, and Amira Lateef Abdullah. "Modelling, validation and analyzing performance of serpentine-direct PV/T solar collector design." CFD Letters 11, no. 2 (2019): 50-65.

[11] Hassan, Zulkurnain, Mohd Suffian Misaran@Misran, Nancy Julius Siambun, Ag Sufiyan Abd Hamid, and Mohd Amran Madlan. "Feasibility of using Solar PV Waste Heat to Regenerate Liquid Desiccant in Solar Liquid Desiccant Air Conditioning System." Journal of Advanced Research in Experimental Fluid Mechanics and Heat Transfer 2, no. 1 (2020): 10-16.

[12] Rosli, Mohd Afzanizam Mohd, Yew Wai Loon, Muhammad Zaid Nawam, Suhaimi Misha, Aiman Roslizar, Faridah Hussain, Nurfaizey Abdul Hamid, Zainal Arifin, and Safarudin Gazali Herawan. "Validation Study of Photovoltaic Thermal Nanofluid Based Coolant Using Computational Fluid Dynamics Approach." CFD Letters 13, no. 3 (2021): 5871. https://doi.org/10.37934/cfdl.13.3.5871

[13] Norouzi, Amir Mohammad, Majid Siavashi, and MohammadHasan Khaliji Oskouei. "Efficiency enhancement of the parabolic trough solar collector using the rotating absorber tube and nanoparticles." Renewable Energy 145 (2020): 569-584. https://doi.org/10.1016/j.renene.2019.06.027

[14] Bezaatpour, Mojtaba, and Hadi Rostamzadeh. "Design and evaluation of flat plate solar collector equipped with nanofluid, rotary tube, and magnetic field inducer in a cold region." Renewable Energy 170 (2021): 574-586. https://doi.org/10.1016/j.renene.2021.02.001

[15] Bezaatpour, Mojtaba, and Hadi Rostamzadeh. "Simultaneous energy storage enhancement and pressure drop reduction in flat plate solar collectors using rotary pipes with nanofluid." Energy and Buildings 239 (2021): 110855. https://doi.org/10.1016/i.enbuild.2021.110855

[16] Bezaatpour, Mojtaba, Hadi Rostamzadeh, and Javad Bezaatpour. "Hybridization of rotary absorber tube and magnetic field inducer with nanofluid for performance enhancement of parabolic trough solar collector." Journal of Cleaner Production 283 (2021): 124565. https://doi.org/10.1016/i.jclepro.2020.124565

[17] Duffie, John A., and William A. Beckman. Solar Engineering of Thermal Processes. John Wiley \& Sons, 2013. https://doi.org/10.1002/9781118671603

[18] Verma, Sujit Kumar, Kamal Sharma, Naveen Kumar Gupta, Pawan Soni, and Neeraj Upadhyay. "Performance comparison of innovative spiral shaped solar collector design with conventional flat plate solar collector." Energy 194 (2020): 116853. https://doi.org/10.1016/i.energy.2019.116853 
[19] Davidzon, Michael I. "Newton's law of cooling and its interpretation." International Journal of Heat and Mass Transfer 55, no. 21-22 (2012): 5397-5402. https://doi.org/10.1016/i.ijheatmasstransfer.2012.03.035

[20] Sansaniwal, Sunil Kumar, Vashimant Sharma, and Jyotirmay Mathur. "Energy and exergy analyses of various typical solar energy applications: A comprehensive review." Renewable and Sustainable Energy Reviews 82 (2018): 15761601. https://doi.org/10.1016/j.rser.2017.07.003 